\title{
Myotonic dystrophy presenting as severely dilated cardiomyopathy with out-of-hospital cardiac arrest
}

\author{
M. Isrie · L. Wong · J. M. van Hagen · A. C. Houweling
}

Published online: 27 November 2018

(c) The Author(s) 2018

A 52-year-old female was admitted after an out-ofhospital cardiac arrest due to ventricular fibrillation. Cardiological evaluation revealed non-ischaemic dilated cardiomyopathy (DCM). Cardiac MRI showed a severely dilated left ventricle with an ejection fraction of $17 \%$ (Fig. 1a). Normal coronary arteries were seen on the coronary angiogram. Her medical history revealed cataracts at the age of 48 years and diminished strength in her hands. Two of her sisters had been diagnosed with myotonic dystrophy (MD). Their children had a more severe phenotype including clubfeet and developmental delay (Fig. 1b). Analysis of 53 cardiomyopathy-related genes using next-generation sequencing did not reveal any pathogenic variants. Analysis of the (CTG) $n$ repeat in the $D M P K$ gene ( $n>150$ ) revealed a heterozygous expansion, confirming the diagnosis of MD in our patient. A CTG repeat length between 100 and 1,000 is associated with the classic type of MD with muscle weakness and wasting, myotonia, cataracts and cardiac conduction abnormalities. DCM and ventricular fibrillation are previously reported but rare features of MD [1-5].
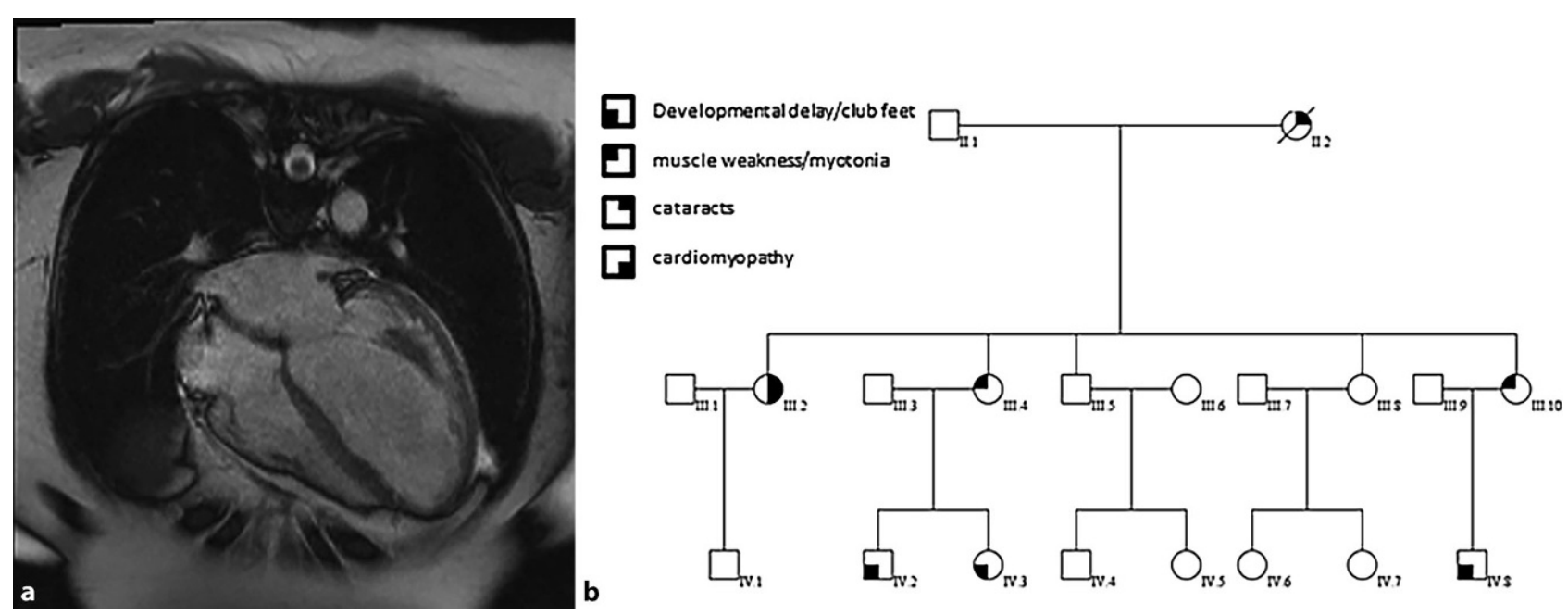

Fig. 1 Cardiac MRI (a) and pedigree (b)

M. Isrie $(\bowtie) \cdot$ J. M. van Hagen · A. C. Houweling

Department of Clinical Genetics, VU University Medical

Centre, Amsterdam, The Netherlands

m.misra@vumc.nl

L. Wong

Department of Cardiology, VU University Medical Centre,

Amsterdam, The Netherlands 
Conflict of interest M. Isrie, L. Wong, J.M. van Hagen and A.C. Houweling declare that they have no competing interests.

Open Access This article is distributed under the terms of the Creative Commons Attribution 4.0 International License (http://creativecommons.org/licenses/by/4.0/), which permits unrestricted use, distribution, and reproduction in any medium, provided you give appropriate credit to the original author(s) and the source, provide a link to the Creative Commons license, and indicate if changes were made.

\section{References}

1. GunkelO, Reichenbach H, Thamm B, etal. Late diagnosis of Curschmann-Steinert myotonic dystrophy in a female pa- tient with dilated cardiomyopathy and in her son. Z Kardiol. 2000;89(7):599-605.

2. Premawardhana L, Thirunavakarasu G. Myotonia dystrophica-first presentation as severe left ventricular failure complicating dilated cardiomyopathy. Postgrad Med J. 1992;68:67.

3. Lin A, Mitchell F, Fitz F, et al. Dilated cardiomyopathy in myotonic dystrophy. J Am Coll Cardiol. 1989;13:262-3.

4. Perloff J, Stevenson W, Roberts N, et al. Cardiac involvement in myotonic muscular dystrophy (Steinert's disease): a prospective study of 25 patients. Am J Cardiol. 1984;54:1074-81.

5. Pelargonio G, Dela Russo A, Sanna T, et al. Myotonic dystrophy and the heart. Heart. 2002;88:665-70. 